International Journal of Applied Dental Sciences 2021; 7(3): 224-227

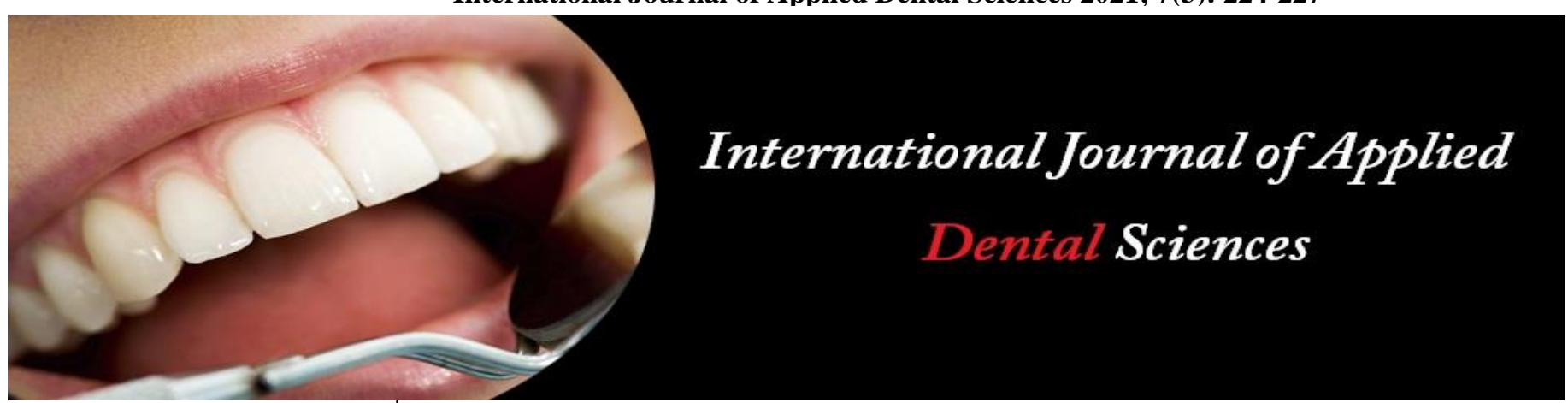

ISSN Print: 2394-7489

ISSN Online: 2394-7497

IJADS 2021; 7(3): 224-227

(C) 2021 IJADS

www.oraljournal.com

Received: 04-05-2021

Accepted: 06-06-2021

Zenaida Carolina Garcia Castañeda Master in Sciences Student, Universidad Autonoma de Nuevo Leon, Facultad de Odontologia, Monterrey, Nuevo Leon, CP, Mexico

Luis Martín Vargas Zuñiga Professor, Universidad Autónoma de Guerrero, Facultad de

Odontología. Acapulco de Juárez de Guerrero, México

Juan Manuel Luna Gomez

Professor, Universidad Autónoma de Guerrero, Facultad de

Odontología. Acapulco de Juárez de Guerrero, México

Claudio Cabral Romero

Professor, Universidad Autonoma de Nuevo Leon, Facultad de Odontologia, Monterrey, Nuevo Leon, CP, Mexico

Rene Hernandez Delgadillo Professor, Universidad Autonoma de Nuevo Leon, Facultad de Odontologia, Monterrey, Nuevo Leon, CP, Mexico

Rosa Isela Sanchez-Najera Professor, Universidad Autonoma de Nuevo Leon, Facultad de Odontologia, Monterrey, Nuevo Leon, CP, Mexico

Juan Manuel Solis-Soto Professor, Universidad Autonoma de Nuevo Leon, Facultad de Odontologia, Monterrey, Nuevo Leon, CP, Mexico
Corresponding Author: Juan Manuel Solis-Soto Professor, Universidad Autonoma de Nuevo Leon, Facultad de Odontologia, Monterrey, Nuevo Leon, CP, Mexico

\section{Filifactor alocis in endodontic infections}

\section{Zenaida Carolina Garcia Castañeda, Luis Martín Vargas Zuñiga, Juan Manuel Luna Gomez, Claudio Cabral Romero, Rene Hernandez Delgadillo, Rosa Isela Sanchez-Najera and Juan Manuel Solis-Soto}

DOI: $\underline{\text { https://doi.org/10.22271/oral.2021.v7.i3d.1303 }}$

\section{Abstract}

Introduction: Filifactor alocis is considered an emerging pathogen in various oral infections, mainly endodontic.

Objective: To analyze the literature on the bacterium Filifactor alocis, including its virulence factors, nutrition, diagnosis, epidemiology, and treatment.

Methodology: Articles on the subject published through the PubMed, SCOPUS and Google Academic databases were analyzed, with an emphasis on the last 5 years. It was carried out with the words "Filifactor alocis", "Gram-positive", "Anaerobic bacteria", "Endodontic infections".

Results: 3-methyldenine DNA glycosylase, its ability to encode FtxA exotoxin, and its high ability to form hydrogen sulfide from L-cysteine are some of its virulence factors. 16S rRNA gene sequencing is the most common detection method. The relatively high detection of $F$. alocis associated with infections of endodontic origin, makes it a potential putative endodontic pathogen. Correct chemical-mechanical instrumentation and a hermetic seal is the best treatment to eradicate Filifactor alocis.

Conclusions: Filifactor alocis is one of the most frequent bacteria in various endodontic infections. Therefore, its eradication is crucial to achieve the elimination of the infection.

Keywords: Filifactor alocis, gram-positive, anaerobic bacteria, endodontic infections

\section{Introduction}

For a better prognosis of root canal system treatment, adequate knowledge of the microbial flora of the root, especially the apical portion, is necessary ${ }^{[1]}$. Traditionally, microbiological examination of the endodontic microbiota was based on culture techniques. The presence of a variety of bacterial species has been reported in infected root canals. Historically, the most predominant species in endodontically treated teeth with persistent/secondary infections were considered gram-positive facultative anaerobes [2]. Filifactor alocis, an asaccharolytic anaerobic gram-positive bacillus ${ }^{[3]}$, was first isolated as Fusobacterium alocis from the human gingival sulcus in $1985^{[4]}$; it was later reclassified as $F$. alocis ${ }^{[5]}$. It has a slow and low growth rate ${ }^{[6]}$. Whose specific factors can modulate multiple changes in the microbial community and host cell proteome. It is likely that such variations at the molecular level are responsible for the functional changes necessary to mediate the pathogenic process ${ }^{[7]}$. This bacterium has been implicated as a pathogen of the oral cavity, due to its high arrest in primary and persistent endodontic / secondary and periodontal infections $[8,9,10]$. In order to treat endodontic infections correctly, it is necessary to have a thorough knowledge of the causative agents. The aim of this review is to analyze the literature on the bacterium Filifactor alocis, including its virulence factors, nutrition, diagnosis, epidemiology and treatment.

\section{Materials and Methods}

Articles on the subject published through the PubMed, SCOPUS and Google Scholar databases were analyzed, with emphasis on the last 5 years. The quality of the articles was evaluated using PRISMA guidelines, i.e., identification, review, choice and inclusion. The quality of the reviews was assessed using the measurement tool for evaluating systematic reviews (AMSTAR-2) ${ }^{[11]}$. The search was performed using Boolean logical operators AND, OR and NOT. 
It was realized with the words "Filifactor alocis", "Grampositive", "Anaerobic bacteria", "Endodontic infections". The keywords were used individually, as well as each of them related to each other.

\section{Results \& Discussion \\ 3.1 Virulence factors}

Many factors influence $F$. alocis to colonize, survive and compete with other species, such as, the presence of other microbial species and various prevailing conditions, including fluctuations in nutrient availability, temperature, $\mathrm{pH}$ and oxygen tension ${ }^{[7]}$. One of the key attributes of $F$. alocis is 3methyldenin DNA glycosylation (HMPREF0389_1529), an enzyme reported to be involved in resistance to oxidative and nitrosative stress in other pathogenic bacteria ${ }^{[12,13]}$. F. alocis has a high capacity to form hydrogen sulfide from L-cysteine. This volatile sulfur compound is considered highly cytotoxic and may also be a potential virulence factor of this bacterium [14]. Also, the exotoxin FtxA, which belongs to the RTX family, is associated with multiple oral infections [15]. However, the mechanisms of pathogenicity and virulence factors of $F$. alocis are poorly understood. It is possible that lipopolysaccharides, enzymes and metabolic end products, in particular butyrate, play a role as virulence ${ }^{[10]}$. The relatively high detection of $F$. alocis associated with infections of endodontic origin implies that this species may be involved in the pathogenesis and/or maintenance of periradicular diseases ${ }^{[10]}$. It has also been discovered in the canals of endodontically treated pieces with periapical lesions, is associated with signs and symptoms of endodontic infections ${ }^{[6]}$, and has been identified as one of the prevalent phylotypes in root canal treatment failure ${ }^{[16]}$.

$F$. alocis is considered to have virulence factors that allow it to compete with other species allowing it to colonize and survive in the root canal system. DNA glycosylation of 3methyldenin, its ability to encode FtxA exotoxin and its high capacity to form hydrogen sulfide from L-cysteine are some virulence factors attributed to Filifactor alocis.

\subsection{Nutrition}

Bacteria are one of the main causes of pulpal problems and have different methods of penetrating and invading the endodontic space. The types of bacteria encountered vary from facultative anaerobes to aerobes ${ }^{[17]}$. These root canal bacteria can be isolated as planktonic cells, suspended in the liquid phase of the root canal, ${ }^{[18]}$ or grow mainly in biofilms, aggregates and sessile coaggregates ${ }^{[19]}$. They are located in privileged positions within the root canal system, protected from the action of host defense cells, where they must find resources or nutrients to survive ${ }^{[20,21]}$. The apical third of the root canal favors the establishment of strictly anaerobic bacteria, such as Filifactor alocis. Furthermore, these bacteria located in the apical part of the root canal can obtain various nutrients from tissue fluids and inflammatory exudate ${ }^{[22]}$. The filtration of such inflammatory exudate is rich in proteins and glycoproteins. This favors the establishment of proteolytic bacteria and/or bacteria that use peptides or amino acids as energy sources. The collective metabolic activity of anaerobic bacteria further contributes to low redox potential conditions leading to an increased expression of virulence by some anaerobic pathogens ${ }^{[23]}$. Therefore, it is expected that a different microbial composition will be observed in the microbiota colonizing the different regions of the canal, with a higher dominance in the apical canal of anaerobic bacteria, which use proteins, peptides and amino acids as energy sources, as is the case of Filifactor alocis ${ }^{[22]}$.

Filifactor alocis is located mainly in the apical third of the root canal, where it favors its establishment, as well as its capacity to obtain various nutrients from tissue fluids and inflammatory exudate, rich in proteins and glycoproteins.

\subsection{Diagnosis}

Traditionally, endodontic infections have been studied by culture methods, but the limitations of these methods may have hindered knowledge about the composition of the endodontic microbiota in different types of infection [24]. Consequently, molecular techniques allow a more reliable identification of various bacterial species [25], including culturable/non-culturable and even uncharacterized bacterial community members, as well as poorly prevalent species ${ }^{[26]}$. The 16S rRNA gene has been used for rapid identification of known and unknown bacterial species ${ }^{[27,28]}$. Other molecular methods such as wide-range PCR followed by cloning and sequencing and, more recently, the massively parallel 454 pyrosequencing approach, can also be used to detect complex endodontic microbiota with improved specificity and sensitivity ${ }^{[29,30]}$. Anaerobic species, especially some difficultto-culture bacteria, such as Filifactor alocis, have been more regularly detected in root canals of teeth with failed endodontic treatments, based on the polymerase chain reaction ${ }^{[22]}$. The detection of Filifactor alocis through these molecular methods is high ${ }^{[10,16]} . F$. alocis is an anaerobic gram-positive bacillus that is commonly associated with odontogenic infectious diseases. However, this species possibly stains as gram-negative. In the laboratory, F. alocis grows at $37 \mathrm{C}$ in brain-heart infusion broth supplemented with yeast extract $(0.5 \mathrm{mg} / \mathrm{ml})$, L-cysteine $(50 \mathrm{mg} / \mathrm{ml})$ and $20 \%$ arginine; it requires an anaerobic environment comprising $10 \%$ of $\mathrm{H} 2,10 \%$ of $\mathrm{CO} 2$ and $80 \%$ of $\mathrm{N} 2$. Due to its demanding nature, isolation of $F$. alocis is difficult using traditional culture techniques ${ }^{[31,32]}$.

Sequencing of the $16 \mathrm{~S}$ rRNA gene can be a valuable approach for the detection of bacteria, such as $F$. alocis, that are difficult to identify using standard microbiological laboratory procedures.

\subsection{Epidemiology}

$F$. alocis is one of the common members associated with various endodontic infections ${ }^{[33,34,35]}$. F. alocis has been detected in $46 \%$ of root canals with primary endodontic infections and $24 \%$ of root canals with secondary infections [6], also was detected in $24 \%$ of canals with failed endodontic treatment, suggesting further studies to elucidate the role of these species in persistent endodontic infections. F. alocis was associated with pain, swelling, abscesses, wet canals and purulent exudate ${ }^{[10]}$. F. alocis is present in 12/21 (57.1\%) root canal samples from teeth with asymptomatic periradicular lesions and in 3/10 (30\%) samples taken from root canals associated with acute apical periodontitis. Eight out of 19 $(42.1 \%)$ pus samples revealed the amplicon, specific to $F$. alocis. It has been isolated in nine cases ( 6 asymptomatic and 3 abscesses), six samples (3 asymptomatic and 3 abscesses) ${ }^{[22]}$. Likewise, F. alocis was associated with sinus tracts ${ }^{[36]}$. $F$. alocis is currently frequently detected in cases of endodontic failure, can be associated with certain clinical characteristics and exert a synergistic relationship with $P$. endodontalis, $P$. gingivalis and $T$. denticola, which could be involved in the pathogenesis of endodontic treatments ${ }^{[22,37]}$. The epidemiology of $F$. alocis represents much controversy because of the various diagnostic methods, therefore, it is not 
possible to give real information about the epidemiology of this bacterium. However, reports indicate a relatively high detection, associated with infections of endodontic origin being implicated in the pathogenesis and / or maintenance of periradicular diseases. Because of this, F. alocis has the potential to be a putative endodontic pathogen.

\subsection{Treatment}

The chemomechanical preparation is intended to clean, disinfect and shape the root canal. This step is of utmost importance during the treatment of infected teeth, because the treatment outcome depends on the efficacy of bacterial elimination, its products, and pulp tissue debris ${ }^{[38]}$. Endodontic instrumentation alone cannot achieve a sterile condition due to the anatomical complexities of root canals. It is recommended to implement irrigants such as EDTA ${ }^{[39]}$ and sodium hypochlorite ${ }^{[40]}$, which is the most recommended irrigant ${ }^{[41]}$, also the implementation of chlorhexidine, as well as intaraconductive medications, such as triple antibiotic paste (combination of metronidazole, ciprofloxacin and minocycline) ${ }^{[42,43]}$.

Minocycline has a broad antimicrobial spectrum against aerobic and anaerobic bacteria, as well as gram negative and gram positive bacteria, and excellent tissue distribution ${ }^{[44]}, F$. alocis have susceptibility to such antibiotic ${ }^{[45]}$. However, some bacteria may remain in the duct. Therefore, a tight seal of the canal space is required to bury any residual bacteria and eventually eliminate them ${ }^{[46]}$. Root canal obturation is performed after microbial control to prevent re-infection or re-emergence of the root canal after chemo-mechanical disinfection procedures. The goal is to keep the (low) microbial load remaining after treatment below the threshold of disease expression, and to prevent the entry of periapical fluids that nourish the surviving microbes in the canal space [47].

Close communication between bacteria and living host tissue in the apical area is not sufficient to eliminate root canal infection. Defense molecules and leukocytes hardly have access to the infection due to poor circulation in the necrotic pulp tissue ${ }^{[40]}$. Although the immune system employs different measures to overcome root canal and periradicular infection, these measures are useless to eradicate the causative factor. For now, removal of the microbial biofilm by endodontic treatment is the best way to restore the health of the periradicular tissue ${ }^{[48]}$.

To eradicate a bacterium such as Filifactor alocis, it is strictly necessary to implement an effective chemical-mechanical cleaning, as well as a hermetic sealing of the root canal, since the host defenses are unable to eliminate the infection on their own. The use of an intra-canal medication such as triple antibiotic paste can be effective, since it contains minocycline to which Filifactor alocis is susceptible.

\section{Conclusions}

Filifactor alocis is an anaerobic bacillus, with an ability to obtain various nutrients in the apical third of the root canal, DNA glycosylation of 3-methyldenin, its ability to encode FtxA exotoxin and its high capacity to form hydrogen sulfide from L-cysteine are some of its virulence factors. Sequencing of the 16S rRNA gene is the most suitable detection method. The relatively high detection of $F$. alocis associated with infections of endodontic origin makes it a potential putative endodontic pathogen. Correct chemical-mechanical instrumentation and hermetic sealing is the best treatment to eradicate Filifactor alocis.

\section{References}

1. Tatikonda A, Sudheep N, Biswas KP, Gowtham K, Pujari S, Singh P. Evaluation of Bacteriological Profile in the Apical Root Segment of the Patients with Primary Apical Periodontitis. J Contemp Dent Pract 2017;18(1):44-48.

2. Siqueira JF Jr, Rôças IN, Alves FR, Silva MG. Bacteria in the apical root canal of teeth with primary apical periodontitis. Oral Surg Oral Med Oral Pathol Oral Radiol Endod 2009;107(5):721-6.

3. Song MK, Kim HY, Choi BK, Kim HH. Filifactor alocis-derived extracellular vesicles inhibit osteogenesis through TLR2 signaling. Mol Oral Microbiol 2020;35(5):202-210.

4. Cato EP, Moore LVH, Moore WEC. Fusobacterium alocis sp. nov. And Fusobacterium sulci sp. nov. From the human gingival sulcus. Int $\mathrm{J}$ Syst Bacteriol 1985;35:475e7.

5. Jalava J, Eerola E. Phylogenetic analysis of Fusobacterium alocis and Fusobacterium sulci based on 16S rRNA gene sequences: proposal of Filifactor alocis (Cato, Moore and Moore) comb. nov. and Eubacterium sulci (Cato, Moore and Moore) comb. nov. Int J Syst Bacteriol 1999;49:1375e9.

6. Gomes BP, Jacinto RC, Pinheiro ET, Sousa EL, Zaia AA, Ferraz CC, et al. Molecular analysis of Filifactor alocis, Tannerella forsythia and treponema denticola associated with primary endodontic infections and failed endodontic treatment. J Endod. 2006;32(10):937-40.

7. Aruni W, Chioma O, Fletcher HM. Filifactor alocis: The newfound boy on the block with special talents. J. Dent Res 2014;93(8):725-32.

8. Gomes BP, Louzada LM, Almeida-Gomes RF, Pinheiro ET, Sousa ELR, Jacinto RC, et al. Investigation of Filifactor alocis in primary and in secondary endodontic infections: A molecular study. Arch Oral Biol 2020;118:104826.

9. Wang Q, Wright CJ, Dingming H, Uriarte SM, Lamont RJ. Oral community interactions of Filifactor alocis in vitro. PLoS One 2013;8(10):e76271.

10. Siqueira JF Jr, Rôças IN. Detection of Filifactor alocis in endodontic infections associated with different forms of periradicular diseases. Oral microbiol immunol 2003;18(4):263-5.

11. Shea BJ, Reeves BC, Wells G, Thuku M, Hamel C, Moran J, et al. AMSTAR 2: A critical appraisal tool for systematic reviews that include randomised or nonrandomised studies of healthcare interventions, or both. BMJ 2017;358: j4008.

12. Slade D, Radman M. Oxidative stress resistance in Deinococcus radiodurans. Microbiol Mol Biol Rev 2011;75(1):133-91.

13. Aruni AW, Roy F, Fletcher HM. Filifactor alocis has virulence attributes that can enhance its persistence under oxidative stress conditions and mediate invasion of epithelial cells by porphyromonas gingivalis. Infect Immun 2011;79(10):3872-86.

14. Persson S, Edlund MB, Claesson R, Carlsson J. The formation of hydrogen sulfide and methyl mercaptan by oral bacteria. Oral Microbiol Immunol 1990;5(4):195201.

15. Oscarsson J, Claesson R, Bao K, Brundin M, Belibasakis GN. Phylogenetic Analysis of Filifactor alocis Strains Isolated from Several Oral Infections Identified a Novel RTX Toxin, FtxA. Toxins (Basel) 2020;12(11):687.

16. Zhang C, Hou BX, Zhao HY, Sun Z. Microbial diversity 
in failed endodontic root-filled teeth. Chin Med J (Engl) 2012;125(6):1163-8. PMID: 22613548.

17. Dioguardi M, Di Gioia G, Illuzzi G, Arena C, Caponio VCA, Caloro GA, et al. Inspection of the Microbiota in Endodontic Lesions. Dent J (Basel) 2019;7(2):47.

18. Prada I, Micó-Muñoz P, Giner-Lluesma T, MicóMartínez P, Collado-Castellano N, Manzano-Saiz A. Influence of microbiology on endodontic failure. Literature review. Med Oral Patol Oral Cir Bucal 2019;24(3):e364-e372.

19. Costerton W, Veeh R, Shirtliff M, Pasmore M, Post C, Ehrlich G. The application of biofilm science to the study and control of chronic bacterial infections. J Clin Invest 2003;112(10):1466-77.

20. Siqueira JF Jr. Endodontic infections: concepts, paradigms, and perspectives. Oral Surg Oral Med Oral Pathol Oral Radiol Endod 2002;94(3):281-93.

21. Nair PNR. Light and electron microscopic studies of root canal flora and periapical lesions. J Endod 1987;13(1):29-39.

22. Siqueira JF Jr, Rôças IN. Polymerase chain reaction based analysis of microorganisms associated with failed endodontic treatment. Oral Surg Oral Med Oral Pathol Oral Radiol Endod 2004;97(1):85-94.

23. Ruby J, Goldner M. Nature of symbiosis in oral disease. $\mathbf{J}$ Dent Res 2007;86:8-11.

24. Siqueira JF Jr, Rôças IN. Exploiting molecular methods to explore endodontic infections. Part 1. Current molecular technologies for microbiological analysis. J Endod 2005;31:411-23.

25. Gomes BP, Pinheiro ET, Jacinto RC, Zaia AA, Ferraz CC, Souza-Filho FJ. Microbial analysis of canals of rootfilled teeth with periapical lesions using polymerase chaine reaction. J Endod 2008;34(5):537-40.

26. Sogin ML, Morrison HG, Huber JA, Mark Welch D, Huse SM, Neal PR, et al. Microbial diversity in the deep sea and the underexplored "rare biosphere". PNAS 2006;103:12115-20.

27. Rôças IN, Siqueira JF Jr. Frequency and levels of candidate endodontic pathogens in acute apical abscesses as compared to asymptomatic apical periodontitis. PLoS One 2018;13(1):e0190469.

28. Siqueira JF Jr, Rôças IN, Paiva SS, Magalhães KM, Guimarães-Pinto T. Cultivable bacteria in infected root canals as identified by $16 \mathrm{~S}$ rRNA gene sequencing. Oral Microbiol Immunol 2007;22(4):266-71.

29. Siqueira JF Jr, Rôças IN. Microbiology and treatment of acute apical abscesses. Clin Microbiol Rev 2013;26(2):255-73.

30. Jacinto RC, Gomes BP, Ferraz CC, Zaia AA, Filho FJ. Microbiological analysis of infected root canals from symptomatic and asymptomatic teeth with periapical periodontitis and the antimicrobial susceptibility of some isolated anaerobic bacteria. Oral Microbiol Immunol 2003; 18(5):285-92.

31. Nakazawa F, Poco SE, Ikeda T, Sato M, Kalfas S, Sundqvist G, et al. Cryptobacterium curtum gen. nov., sp. nov., a new genus of Gram-positive anaerobic rod isolated from human oral cavities. Int J Syst Bacteriol 1999;49:1193e200.

32. Vidya Hiranmayi K, Sirisha K, Ramoji Rao MV, Sudhakar P. Novel pathogens in periodontal microbiology. J Pharm Bio Allied Sci 2017;9:155e63.

33. Li H, Guan R, Sun J, Hou B. Bacteria community study of combined periodontal-endodontic lesions using denaturing gradient gel electrophoresis and sequencing analysis. J Periodontol 2014;85(10):1442-9.

34. Nóbrega LM, Montagner F, Ribeiro AC, Mayer MA, Gomes BP. Molecular Identification of Cultivable Bacteria from Infected Root Canals Associated with Acute Apical Abscess. Braz Dent J 2016;27(3):318-24.

35. Montagner F, Jacinto RC, Signoretti FG, Sanches PF, Gomes BP. Clustering behavior in microbial communities from acute endodontic infections. J Endod 2012;38(2):158-62.

36. Martinho FC, Chiesa WM, Leite FR, Cirelli JA, Gomes BP. Antigenic activity of bacterial endodontic contents from primary root canal infection with periapical lesions against macrophage in the release of interleukin-1beta and tumor necrosis factor alpha. $\mathbf{J}$ Endod 2010;36(9):1467-74.

37. Gomes BP, Pinheiro ET, Jacinto RC, Zaia AA, Ferraz CC, Souza-Filho FJ. Microbial analysis of canals of rootfilled teeth with periapical lesions using polymerase chaine reaction. J Endod 2008;34(5):537-40.

38. Siqueira Junior JF, Rôças IDN, Marceliano-Alves MF, Pérez AR, Ricucci D. Unprepared root canal surface areas: causes, clinical implications, and therapeutic strategies. Braz Oral Res 2018;32(suppl 1):e65.

39. Lee LW, Lan WH. [A clinical evaluation of antimicrobial effectiveness of EDTA as an endosonic irrigant]. Zhonghua Ya Yi Xue Hui Za Zhi 1988;7(3):105-Chinese. PMID: 3152617.

40. Siqueira JF Jr. Endodontic infections: concepts, paradigms, and perspectives. Oral Surg Oral Med Oral Pathol Oral Radiol Endod 2002;94(3):281-93.

41. Estrela C, Estrela CR, Barbin EL, Spanó JC, Marchesan MA, Pécora JD. Mechanism of action of sodium hypochlorite. Braz Dent J 2002;13(2):113-7.

42. Valverde ME, Baca P, Ceballos L, Fuentes MV, RuizLinares M, Ferrer-Luque CM. Antibacterial efficacy of several intracanal medicaments for endodontic therapy. Dent Mater J 2017;36(3):319-324.

43. Vijayaraghavan R, Mathian VM, Sundaram AM, Karunakaran R, Vinodh S. Triple antibiotic paste in root canal therapy. J Pharm Bioallied Sci 2012;4(Suppl 2):S230-3.

44. Chopra I, Roberts M. Tetracycline antibiotics: mode of action, applications, molecular biology, and epidemiology of bacterial resistance. Microbiol Mol Biol Rev 2001;65:232e60.

45. Inubushi $\mathrm{J}$, Liang $\mathrm{K}$. Update on minocycline in vitro activity against odontogenic bacteria. J Infect Chemother 2020;26(12):1334-1337.

46. Shin JH, Lee DY, Lee SH. Comparison of antimicrobial activity of traditional and new developed root sealers against pathogens related root canal. J Dent Sci 2018;13(1):54-59.

47. Shanahan DJ, Duncan HF. Root canal filling using Resilon: a review. Br Dent J 2011;211(2):81-8.

48. Abusrewil S, Alshanta OA, Albashaireh K, Alqahtani S, Nile CJ, Scott JA, et al. Detection, treatment and prevention of endodontic biofilm infections: what's new in 2020? Crit Rev Microbiol 2020;46(2):194-212. 